\title{
Use of Zeolite for Removing Ammonia and Ammonia-Caused Toxicity in Marine Toxicity Identification Evaluations
}

\author{
R. M. Burgess, ${ }^{1}$ M. M. Perron, ${ }^{1,2}$ M. G. Cantwell, ${ }^{1}$ K. T. Ho, ${ }^{1}$ J. R. Serbst, ${ }^{1}$ M. C. Pelletier ${ }^{1}$ \\ 1 United States Environmental Protection Agency, ORD/NHEERL Atlantic Ecology Division, 27 Tarzwell Dr., Narragansett, Rhode Island 02882, \\ USA \\ ${ }^{2}$ Harvard School of Public Health, Department of Environmental Health, 665 Huntington Ave., Boston, Massachusetts 02115, USA
}

Received: 8 January 2004/Accepted: 15 April 2004

\begin{abstract}
Ammonia occurs in marine waters including effluents, receiving waters, and sediment interstitial waters. At sufficiently high concentrations, ammonia can be toxic to aquatic species. Toxicity identification evaluation (TIE) methods provide researchers with tools for identifying aquatic toxicants. For identifying ammonia toxicity, there are several possible methods including $\mathrm{pH}$ alteration and volatilization, Ulva lactuca addition, microbial degradation, and zeolite addition. Zeolite addition has been used successfully in freshwater systems to decrease ammonia concentrations and toxicity for several decades. However, zeolite in marine systems has been used less because ions in the seawater interfere with zeolite's ability to adsorb ammonia. The objective of this study was to develop a zeolite method for removing ammonia from marine waters. To accomplish this objective, we performed a series of zeolite slurry and column chromatography studies to determine uptake rate and capacity and to evaluate the effects of salinity and $\mathrm{pH}$ on ammonia removal. We also assessed the interaction of zeolite with several toxic metals. Success of the methods was also evaluated by measuring toxicity to two marine species: the mysid Americamysis bahia and the amphipod Ampelisca abdita. Column chromatography proved to be effective at removing a wide range of ammonia concentrations under several experimental conditions. Conversely, the slurry method was inconsistent and variable in its overall performance in removing ammonia and cannot be recommended. The metals copper, lead, and zinc were removed by zeolite in both the slurry and column treatments. The zeolite column was successful in removing ammonia toxicity for both the mysid and the amphipod, whereas the slurry was less effective. This study demonstrated that zeolite column chromatography is a useful tool for conducting marine water TIEs to decrease ammonia concentrations and characterize toxicity.
\end{abstract}

Toxicity identification evaluation (TIE) methods are used to characterize and identify the causes of toxicity in freshwater

Correspondence to: R. M. Burgess; email: burgess.robert@epa.gov and marine effluents, receiving waters, interstitial waters, and sediments (Norberg-King et al. 1991; Ankley and SchubauerBerigan 1995; Burgess et al. 1996; Ho et al. 2002). Because of its frequent occurrence in municipal effluents and sediment interstitial waters, ammonia is among the commonly characterized toxicants in TIEs (e.g., Ho et al. 2002). Total ammonia $\left(\mathrm{NH}_{\mathrm{x}}\right)$ consists of the toxic form of ammonia $\left(\mathrm{NH}_{3}\right)$ and the relatively nontoxic ammonium form $\left(\mathrm{NH}_{4}{ }^{+}\right.$) (United States Environmental Protection Agency 1989). The most prevalent form in natural waters, including seawater, is $\mathrm{NH}_{4}{ }^{+}$, and the proportion of $\mathrm{NH}_{3}$ increases with increasing $\mathrm{pH}$ (United States EPA 1989).

In marine TIEs performed on effluents, receiving waters, and interstitial waters, the primary methods for characterizing and identifying ammonia-caused toxicity are the graduated-pH manipulation (Burgess et al. 1996) and the macroalga Ulva lactuca addition (Ho et al. 1999; Pelletier et al. 2001). In the graduated-pH manipulation, sample $\mathrm{pH}$ is altered to determine whether $\mathrm{pH}$-dependent toxicants such as ammonia are present. In the $U$. lactuca addition, the marine algae are exposed to the sample and allowed to metabolize bioavailable ammonia, thus decreasing overall ammonia concentrations. Both the graduated-pH and $U$. lactuca methods have proven to be useful for characterizing ammonia toxicity in marine samples (e.g., Burgess 2000; Ho et al. 1999; Pelletier et al. 2001). However, both methods have disadvantages. The graduated-pH manipulation needs to control seawater $\mathrm{pH}$ and because of the strong buffering capacity of seawater (Millero and Sohn 1992), altering $\mathrm{pH}$ for long time periods can be difficult. In the U. lactuca addition, it is critical to maintain ambient temperature at approximately $15^{\circ} \mathrm{C}$ for the first 24 hours of the exposure; otherwise, the seaweed may begin to deteriorate and create toxic artifacts in the TIE. Furthermore, not all coastal locations have year round access to $U$. lactuca.

An alternative TIE manipulation for marine samples is to use zeolite. Zeolite is a naturally occurring hydrated aluminosilicate mineral composed of symmetrically stacked alumina and silica tetrahedra forming an open and stable three-dimensional structure with a negative charge (Kesraoui-Ouki et al. 1994; Rozic et al. 2000; Burgess et al. 2003). The negative charge allows for the adsorption of certain positively charged ions. In 
aqueous solution, the negative charge is generally neutralized by $\mathrm{Na}^{+}$, however, $\mathrm{NH}_{4}{ }^{+}$is preferentially adsorbed to the zeolite matrix. Zeolite has been used for decades to decrease the concentrations of ammonium in municipal effluents (Mercer et al. 1970) and, more recently, in freshwater TIEs (Durhan et al. 1993; Besser et al. 1998) and marine whole sediment TIEs (Burgess et al. 2003). However, in marine TIEs with aqueous samples such as effluents and interstitial waters, zeolite has received only minor use principally because of the potential for $\mathrm{Na}^{+}$in seawater to outcompete $\mathrm{NH}_{4}{ }^{+}$for sites on the zeolite. Another potential disadvantage of using zeolite in a TIE context is the nonselective zeolite uptake of toxic metals including cadmium, copper, nickel, lead, and zinc (KesraouiOuki et al. 1994). Despite these limitations, the advantages associated with zeolite-including availability, potential for the effective removal of $\mathrm{NH}_{4}{ }^{+}$(and therefore $\mathrm{NH}_{\mathrm{x}}$ ), and relatively easy application-justify a closer examination of the mineral for use in marine TIEs.

The first objective of this study was to determine the efficacy of zeolite for removing ammonia from seawater. We approached this objective by comparing zeolite's performance in both freshwater (i.e., deionized water [DI]) and seawater (i.e., reconstituted seawater $[\mathrm{RS}]$ ) systems. Using a series of slurry and column chromatography studies, the rates of zeolite ammonia uptake and capacity by zeolite were evaluated; the effects of salinity, $\mathrm{pH}$, and zeolite quantity on zeolite performance were examined; and the magnitude of zeolite interactions with toxic metals was measured. Slurry and column chromatography methods were selected for comparison because the slurry method is the quickest and simplest form of zeolite manipulation. Conversely, the column method is relatively time consuming and more equipment intensive. However, the slurry method, compared with the column chromatography technique, uses a relatively large amount of zeolite per replicate, which could be prohibitive on a cost basis. The second objective of this research was to assess the mineral's effectiveness at decreasing ammonia toxicity to two marine invertebrates, the mysid Americamysis bahia and the amphipod Ampelisca abdita. Both of these species are commonly used in performing marine TIEs (Burgess et al. 1996; Ho et al. 2002).

\section{Materials and Methods}

\section{Zeolite}

Zeolite was provided by ResinTech (West Berlin, NJ). The specific product used, SIR-600, is the sodium-potassium form of a moist (approximately 10\% water content), granular mineral produced from natural, purified, and back-washed zeolite (0030 to $1.2 \mathrm{~mm}$ particle size). This form of zeolite was used without further preparation unless otherwise indicated. According to the manufacturer, SIR-600 has a selectivity affinity order of $\mathrm{Cs}^{+}>>\mathrm{K}^{+}>\mathrm{NH}_{4}^{+}>>\mathrm{Na}^{+}>\mathrm{Sr}^{2+}$ $>\mathrm{Ca}^{2+}>\mathrm{Mg}^{2+}$

\section{Brine and Deionized Water}

Brine was synthesized in the laboratory by slowly evaporating sandfiltered Narragansett Bay seawater (30\%o) to a salinity of $100 \%$. When needed, brine and DI were used to make $30 \%$ o RS. After preparing the solutions, the salinity was verified using a refractometer.

\section{Ammonia Solutions and Analysis}

Ammonia solutions were prepared using crystalline $\mathrm{NH}_{4} \mathrm{Cl}$ (Aldrich, Milwaukee, WI). Ammonia solutions ranged in concentration from 0 to $750 \mathrm{mg} / \mathrm{L}$. Total ammonia was measured using an Orion ionselective ammonia probe (model no. 9512BN) (Boston, MA) and meter (model no. 720A). The probe was calibrated on the day of analysis using a six-point standard curve prepared with crystalline $\mathrm{NH}_{4} \mathrm{Cl}$ or a $1000-\mathrm{mg} / \mathrm{L}$ standard provided by Orion. $\mathrm{pH}$ was measured using an Orion Ross semimicro pH probe (model no. 8115BN). In general, ammonia concentrations were reported as total ammonia (mg $\mathrm{NH}_{\mathrm{x}} / \mathrm{L}$ ) based on the electrode measurements. In some cases, discussed later, ammonia concentrations were expressed as ammonia $\left(\mathrm{NH}_{3}\right)$ or ammonium $\left(\mathrm{NH}_{4}^{+}\right)$(in $\left.\mathrm{mg} / \mathrm{L}\right)$.

\section{Ammonia Removal Studies}

Two procedures were used to evaluate the ability of zeolite to remove ammonia. In the slurry procedure, an unconfined mass of zeolite was introduced to a beaker containing ammonia in both DI and RS solutions. The beaker was then placed on an orbital shaker and mixed at 75 $\mathrm{rpm}$ at $21^{\circ} \mathrm{C}$ to enhance the interaction of the zeolite and ammonia in solution. During this preliminary uptake study, $5 \mathrm{~mL}$ of solution were collected for ammonia analysis at designated times over a 60 minute time period. For other studies, based on the results of this preliminary ammonia uptake study, the zeolite and ammonia were allowed to interact for approximately 30 minutes before the experiment was ended. In developing the slurry method, several different amounts of zeolite were used. Except where noted in the study on zeolite interaction with metals, results reported in this summary are for the 30 $\mathrm{g} /$ replicate design to allow for comparison with the column chromatography data. Similarly, the volume of the solutions were set at 100 $\mathrm{mL}$ and $100 \mathrm{mg} \mathrm{NH} / \mathrm{L}$ solution. After mixing, zeolite was allowed to settle (for approximately 15 minutes), and samples of solution were collected for ammonia analysis and toxicity testing.

In the column-chromatography procedure, a $30-\mathrm{mL}$ glass syringe (Micro-mate Interchangeable, Popper \& Sons, New Hyde Park, NY) was positioned vertically on a laboratory ring stand and used as a column. Zeolite was soaked in $30 \%$ RS for at least 24 hours before being introduced into the column. A circle of $0.5-\mathrm{mm}$ mesh Nytex (Sefar America Inc., Depew, NY) screening, approximately $1 \mathrm{~cm}$ in diameter, was placed at the base of the interior of the column to retain zeolite as solution passed through, and $30 \mathrm{~g}$ zeolite (wet) was loaded into the column using a spatula. A flow rate of $6 \mathrm{~mL} / \mathrm{min}$ was established using a $125-\mathrm{mL}$ separatory funnel with a Teflon stopcock set to maintain a constant flow. The exception to using this flow rate was in the study on column ammonia uptake. In that study, flow rates varied as follows: $0.75,6,10$, and $20 \mathrm{~mL} / \mathrm{min}$. For all other studies, preparation of the column included rinsing with $50 \mathrm{~mL}$ RS at a gravity-controlled flow rate (i.e., without the separatory funnel). This was followed by $50 \mathrm{~mL}$ RS charged through the column using the separatory funnel to maintain a $6-\mathrm{mL} / \mathrm{min}$ flow rate. Next, the ammonia solution(s) was passed through the column at the $6-\mathrm{mL} / \mathrm{min}$ flow rate except when otherwise noted. Postcolumn solution was collected in a receiving beaker, and samples were collected for both ammonia analysis and toxicity testing. 


\section{Toxicity Testing}

For toxicity testing, up to three treatments were evaluated: unmanipulated, column, and slurry. The column-chromatography and slurry solutions were prepared using the procedures previously described. All toxicity testing replicates used $10 \mathrm{~mL}$ solution in $20-\mathrm{mL}$ beakers (Burgess et al. 1996). For each manipulation, three replicates each with five amphipods, A. abdita, and three replicates each with five mysids, A. bahia, were prepared. Organisms were exposed to ammonia concentrations ranging from below detection to a high nominal concentration of $200 \mathrm{mg} \mathrm{NH} / \mathrm{L}$. Toxicity testing was performed for 48 hours at $30 \%$ and $20^{\circ} \mathrm{C}$ and checked each day for mortality, temperature, and salinity. The mysids were fed Artemia salina daily, but the amphipods were not fed. At the termination of the test, organism survival was determined and reported as percent survival.

\section{Zeolite Interaction With Metals}

A $30 \%$ RS solution consisting nominally of a mixture of $200 \mathrm{ppb}$ each of cadmium, copper, nickel, lead, and zinc was prepared. This solution was then subjected to either the slurry ( $15 \mathrm{~g}$ ) or column-chromatography $(30 \mathrm{~g})$ treatment to evaluate potential metal uptake by the zeolite under the experimental conditions used to remove ammonia. After the slurry or column treatments, water samples were quantified for metals by either graphite furnace atomic absorption spectroscopy (PerkinElmer, Meriden, CT) or inductively coupled plasma-emission spectrometry (Applied Research Laboratories, Valencia, CA). Before analysis, samples were acidified with $1 \mu \mathrm{L}$ concentrated nitric acid $/ \mathrm{mL}$ sample, and detection limits for the study were Cadmium $>0.01$, Copper $>0.4$, Nickel $>1.0$, Lead $>1.0$ and Zinc $>1.0 \mu \mathrm{g} / \mathrm{L}$.

\section{Statistical Analyses}

All experiments were performed in duplicate unless otherwise noted (e.g., toxicity testing where $\mathrm{n}=3$ ), and results were presented as the mean and SD (including the figures). Analysis of variance, followed by the least-significant difference test, was performed to determine if significant differences existed between means of selected experimental treatments $(\propto=0.05)$.

\section{Results and Discussion}

\section{Ammonia Uptake}

For the slurry treatment, zeolite was slightly more effective in removing ammonia from DI compared with RS, but a statistically significant difference between treatments was not detected (Fig. 1). These studies were conducted for up to 1 hour, but only 20 to 30 minutes was required for an apparent equilibrium concentration to be achieved (i.e., ammonia removal did not change significantly with time after 20 minutes $[p<$ 0.05]) for the DI and RS solutions (Fig. 1).

Apparent equilibrium removal of total ammonia was approximately $50 \%$ for both DI and RS. In studies with less zeolite but the same design (e.g., 5 g), the slurry method consistently functioned better with DI compared with RS (data not shown). This suggests that cations in seawater, including $\mathrm{Na}^{+}$and $\mathrm{K}^{+}$, interfere with the $\mathrm{NH}_{4}{ }^{+}$interactions with zeolite-binding sites.
In this design using $30 \mathrm{~g}$ zeolite, these differences were clearly less apparent.

In the column-uptake experiment, four flow rates were evaluated: $0.75,6,10$, and $20 \mathrm{~mL} / \mathrm{min}$. For comparison with the slurry data, these flow rates were converted to solutionzeolite interaction times (in minutes) (Fig. 1). As can be seen, relative to the slurry method, the column rapidly and more effectively removed ammonia from the RS solution. Based on these data, a flow rate of $6 \mathrm{~mL} / \mathrm{min}$ was established as the "standard" flow rate for other experiments. The 6 $\mathrm{mL} / \mathrm{min}$ flow rate was also operationally simple to maintain. The column achieved approximately $90 \%$ removal in 20 minutes of interaction time. Before apparent equilibrium, the column removal rate was approximately $8 \mathrm{mg} / \mathrm{L} / \mathrm{min}$ compared with approximately $2 \mathrm{mg} / \mathrm{L} / \mathrm{min}$ in the DI and RS slurry treatments. These results demonstrated that the column chromatography design affords more effective removal of total ammonia compared with the slurry. Because the zeolite-ammonia interaction is a surface reaction, the column appears to provide greater surface area than the slurry for the reaction to occur.

\section{Capacity}

Using the slurry method in DI solution, the zeolite had a greater capacity for total ammonia compared with its performance in RS (Fig. 2). Total ammonia removal in DI was initially approximately $50 \%$ for approximately $7 \mathrm{mg}$ ammonia and decreased, as the ammonia quantity increased, only to approximately $35 \%$ for $93 \mathrm{mg}$ ammonia. In RS, total ammonia removal was only approximately $15 \%$ for approximately $7 \mathrm{mg}$ ammonia and remained consistently at approximately $25 \%$ as the ammonia quantity increased. As discussed in the ammonia-uptake study, lower total ammonia removal in $\mathrm{RS}$ relative to DI suggests that cations in the seawater are interacting with the zeolite and decreasing the ability for ammonium ions to bind effectively.

In the column-chromatography study, total ammonia removal was also observed to decrease as the amount of ammonia added increased (Fig. 2). Ammonia removal decreased from approximately $95 \%$ with $10 \mathrm{mg}$ added and leveled off at $19 \%$ when $60 \mathrm{mg}$ was added. After adding $80 \mathrm{mg}$ ammonia, breakthrough occurred at approximately $100 \mathrm{mg}$ loading. This suggests that under these conditions, the zeolite binding sites in the column were saturated.

\section{Effects of Salinity}

Zeolite uptake of total ammonia in the slurry showed a decrease with increasing salinity (Fig. 3). Ammonia removal began at approximately $38 \%$ in the $0 \%$ solution (DI) and decreased to approximately $18 \%$ in the $45 \%$ o solution. These results paralleled our observations from the earlier uptake and capacity studies (i.e., zeolite effectiveness is greater in DI than in RS).

In the column design, a decrease in total ammonia removal was also observed as the salinity increased (Fig. 3). The column removed approximately $99 \%$ in the $0 \%$ solution and 


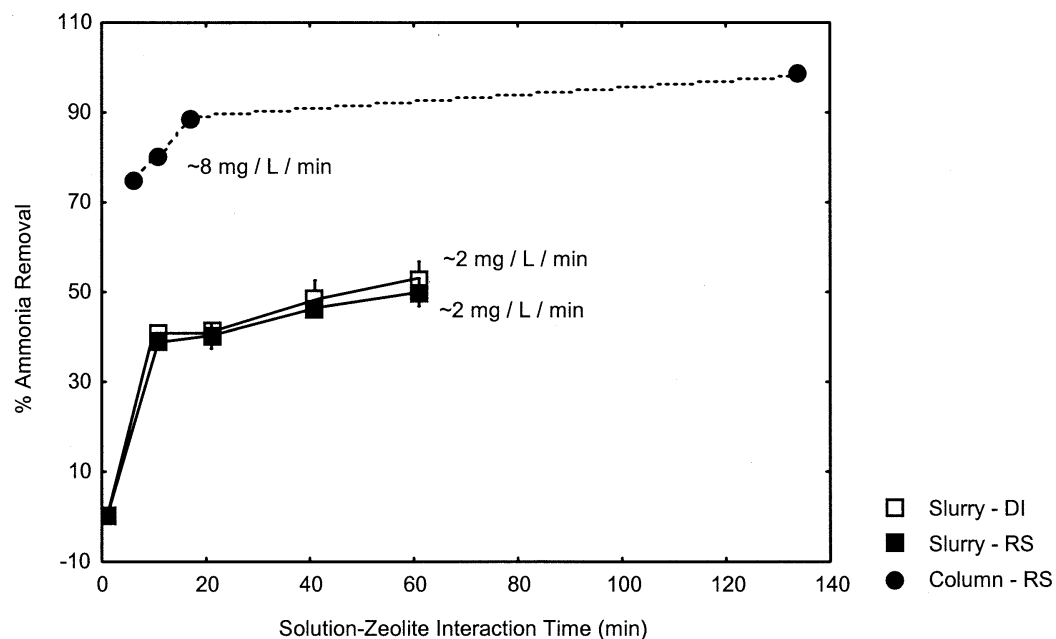

Fig. 1. Comparison of the removal of ammonia by the slurry and column-chromatography methods based on solution-zeolite interaction time

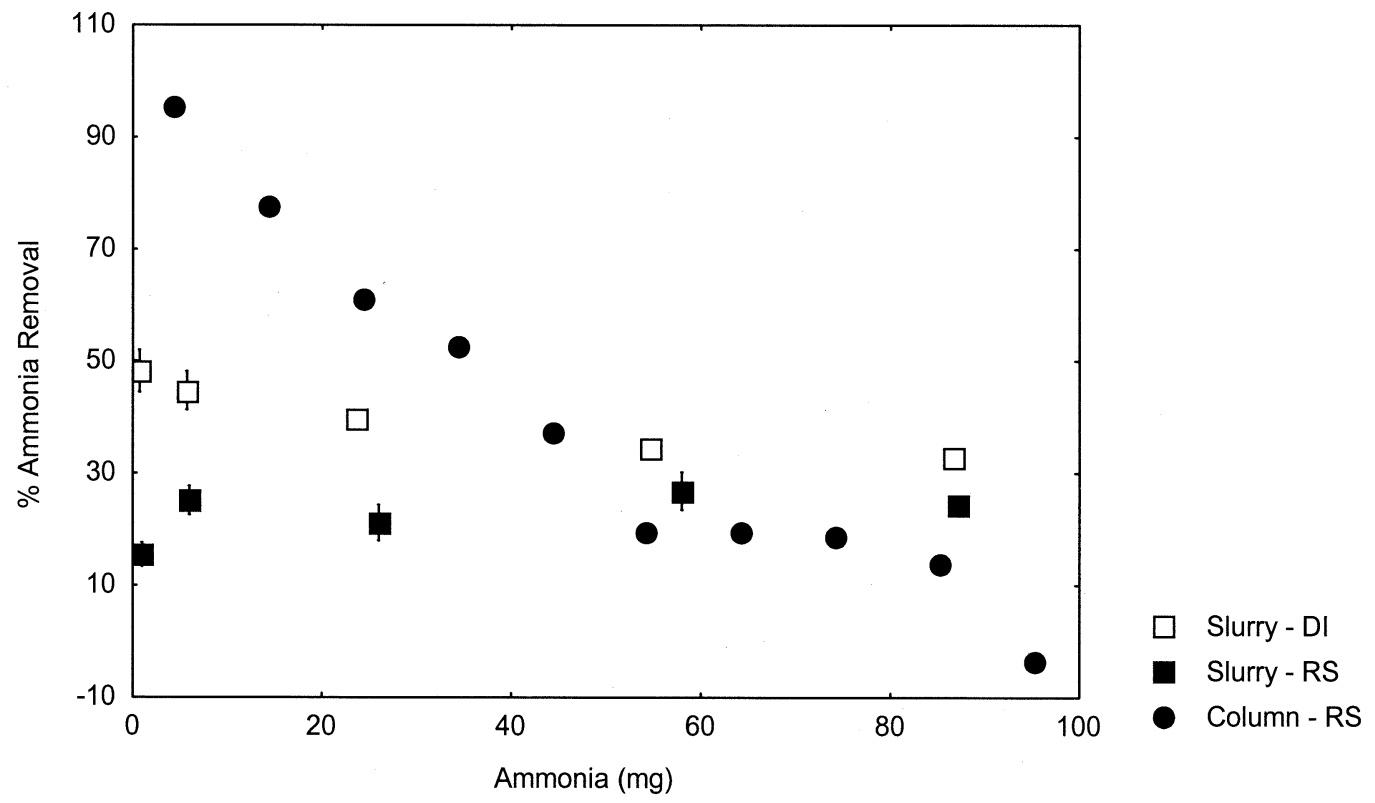

Fig. 2. Comparison of the removal of ammonia by the slurry and column-chromatography methods based on amount of ammonia

decreased to approximately $45 \%$ in the $45 \%$ solution. An apparent equilibrium was also observed at approximately $70 \%$ in the $15 \%$ and $30 \%$ solutions. Despite the greater concentration of competing cations, the column-chromatography method provided greater surface area for zeolite-ammonia interactions relative to the slurry.

\section{Effects of Zeolite Mass}

In the slurry, a direct relationship between the mass of zeolite and total ammonia removal was evident (Fig. 4). In DI, ammonia removal increased from approximately $25 \%$ in the $0.5-\mathrm{g}$ treatment to approximately $80 \%$ removal in the $30 \mathrm{-g}$ treatment. For the RS, an increase in removal of ammonia from approx- imately $15 \%$ to $50 \%$ occurred between the $0.5-$ and $30-\mathrm{g}$ treatments, respectively.

For the column, a similar relationship was observed between the mass of zeolite and the ammonia removed from RS (Fig. 4). Ammonia removal increased from approximately $40 \%$ when using $5 \mathrm{~g}$ zeolite up to approximately $78 \%$ with $30 \mathrm{~g}$ zeolite. Again, presumably these results reflect the greater surface area of zeolite in the column compared with the slurry.

\section{Effects of $\mathrm{pH}$}

Slurry and column chromatography studies to assess the effects of $\mathrm{pH}$ were performed at nominal $\mathrm{pHs}$ of 4.0, 7.0, and 10.0 using $30 \%$ RS. Poststudy $\mathrm{pHs}$ for the slurry method were 


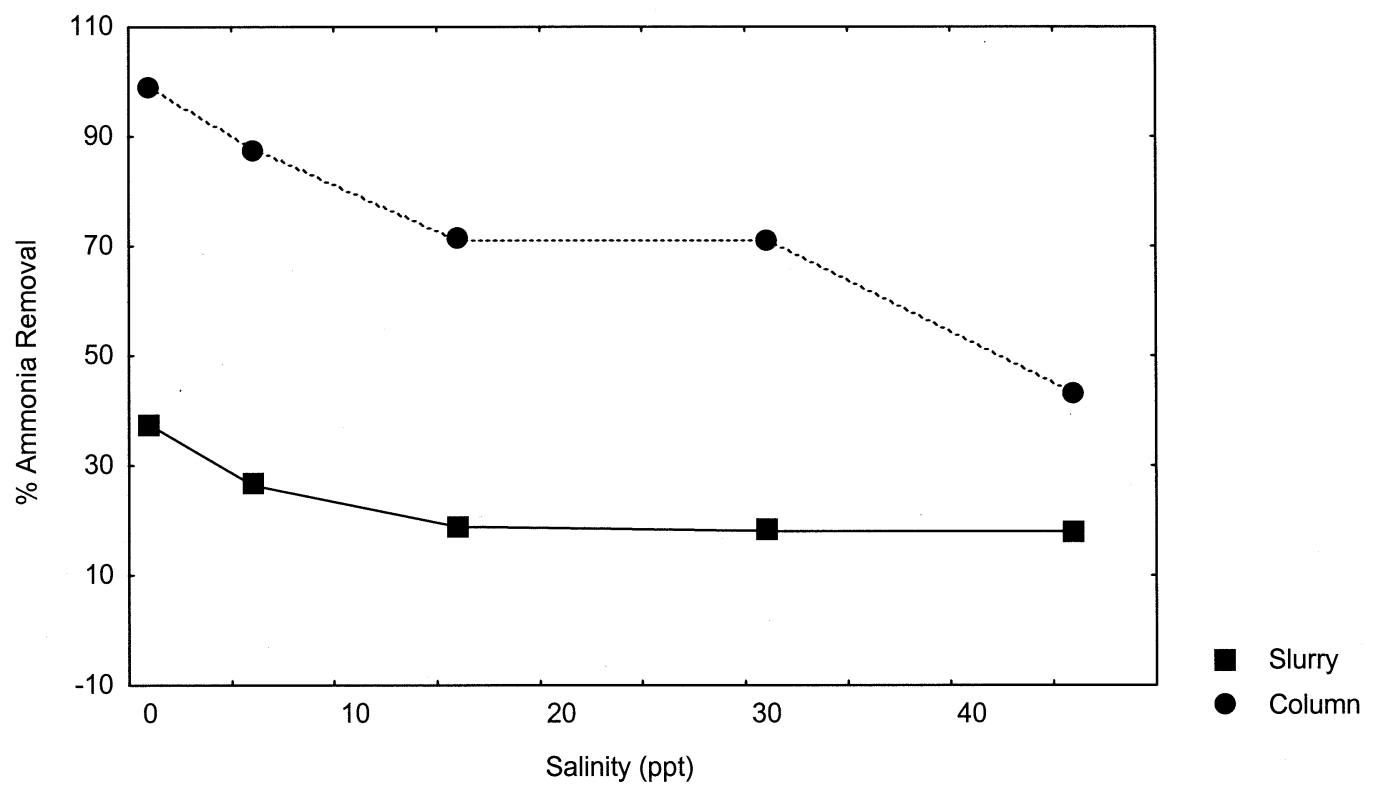

Fig. 3. Comparison of the removal of ammonia by the slurry and column-chromatography methods based on solution salinity

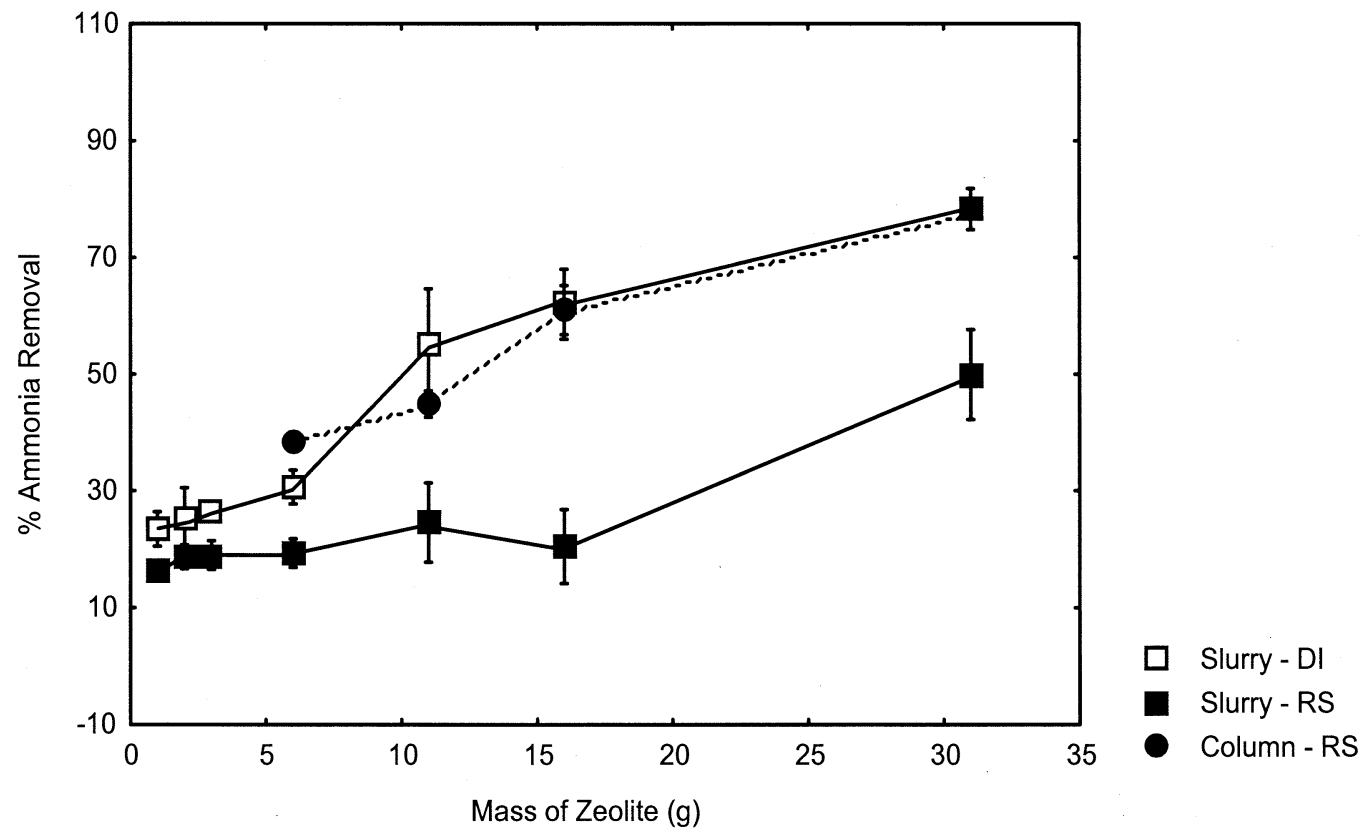

Fig. 4. Comparison of the removal of ammonia by the slurry and column chromatography methods based on mass of zeolite

$5.1 \pm 0.01,7.4 \pm 0.13$, and $9.1 \pm 0.08$ for nominal $\mathrm{pHs} 4,7$, and 10 , respectively. Poststudy $\mathrm{pHs}$ for the column method were $6.7 \pm 0.16,8.0 \pm 0.02$, and $9.4 \pm 0.06$ for nominal $\mathrm{pHs}$ 4,7 , and 10 , respectively. For the slurry, ammonia removal was approximately $40 \%$ (Fig. 5). Effects of $\mathrm{pH}$ on the ability of zeolite to remove ammonia from solution were not noticeable except at $\mathrm{pH}$ 10, where ammonia uptake was increased compared to pHs 4 and 7. This increase was not expected, but it was significant $(p<0.05)$.
Using the column, we observed that $\mathrm{pH}$ did not affect the performance of zeolite in removing total ammonia except for a statistically significant decrease in $\mathrm{pH} 10$ compared with $\mathrm{pH} 4$ and 7 ( $p<0.05$ ) (Fig. 5). We suspect this decrease with $\mathrm{pH} 10$ was caused by the low concentration of $\mathrm{NH}_{4}{ }^{+}$at high pHs. Based on Hampson's model (Hampson 1977), the amount of $\mathrm{NH}_{4}{ }^{+}$at a pH of 10 is only approximately $10 \%$ of $\mathrm{NH}_{x}$ present. Zeolite associates primarily with $\mathrm{NH}_{4}{ }^{+}$, thus, given that the $\mathrm{NH}_{3}$ form of ammonia dominates at higher $\mathrm{pHs}$, less uptake 


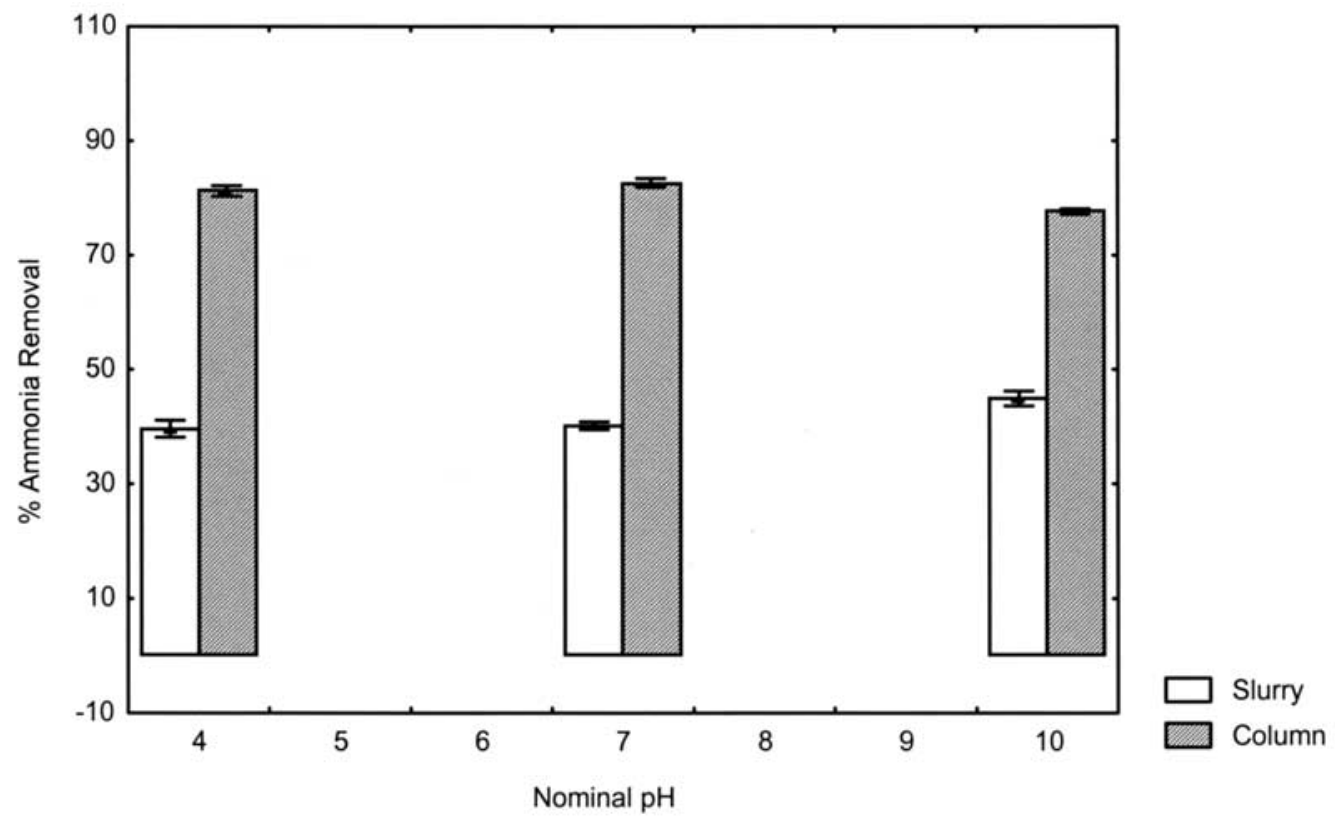

Fig. 5. Comparison of the removal of ammonia by the slurry and column-chromatography methods based on $\mathrm{pH}$

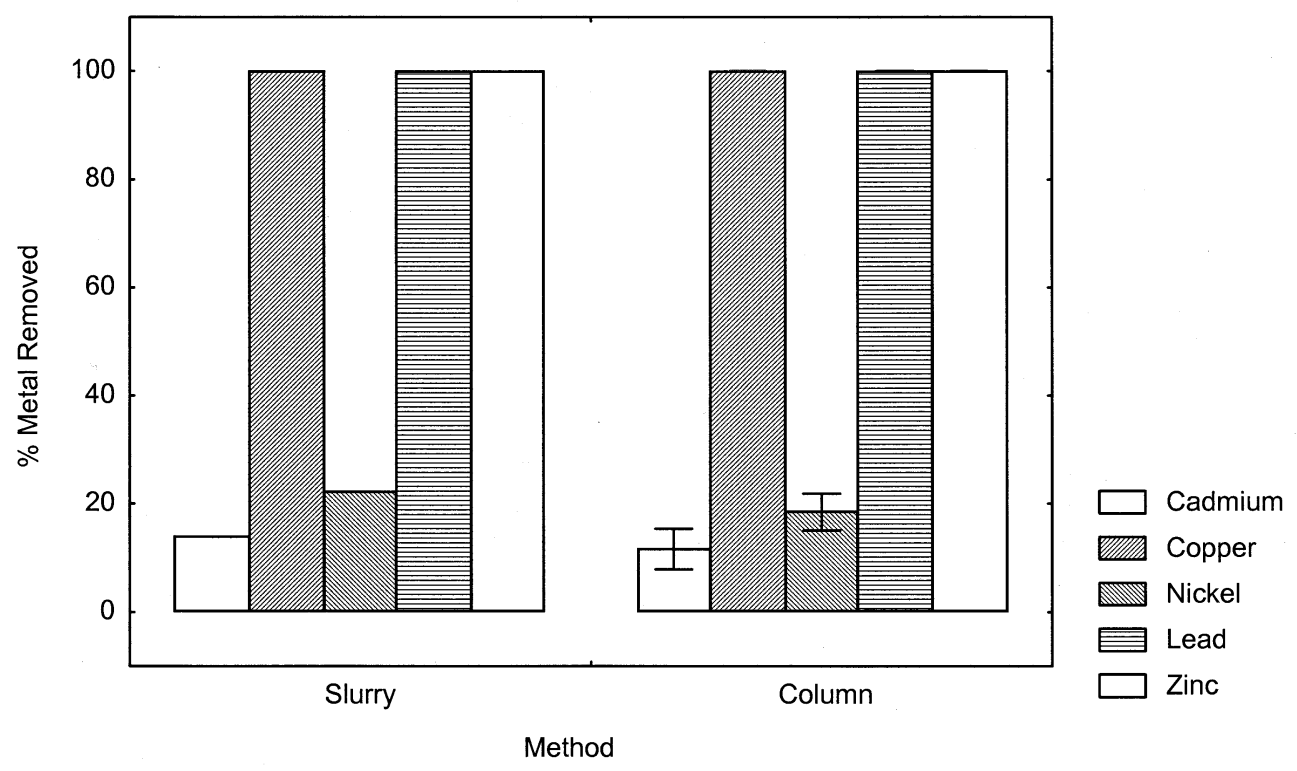

Fig. 6. Comparison of the removal of metals by the slurry $(n=1)$ and column-chromatography methods

will likely occur. Overall, ammonia removal was approximately $80 \%$ for all $\mathrm{pH}$ manipulations in the column design.

\section{Removal of Metals by Zeolite}

Zeolite has been shown to remove several metals from aqueous solution (Kesraoui-Ouki et al. 1994). In this study, we found that the slurry and column methods removed copper, lead, and zinc from RS (Fig. 6). Both methods acted similarly in removing $100 \%$ of all three of these metals while removing only approximately $15 \%$ and $20 \%$ of cadmium and nickel, respectively. Given this, it is critical when using zeolite in a TIE that TIE methods designed for removing metal toxicity are also applied (e.g., ethylenediamine tetraacetic acid [EDTA] addition) (Burgess et al. 1996).

\section{Zeolite Effects on Ammonia Toxicity}

Column chromatography was successful in removing ammonia toxicity for both the mysid and amphipod (Fig. 7A and B), 


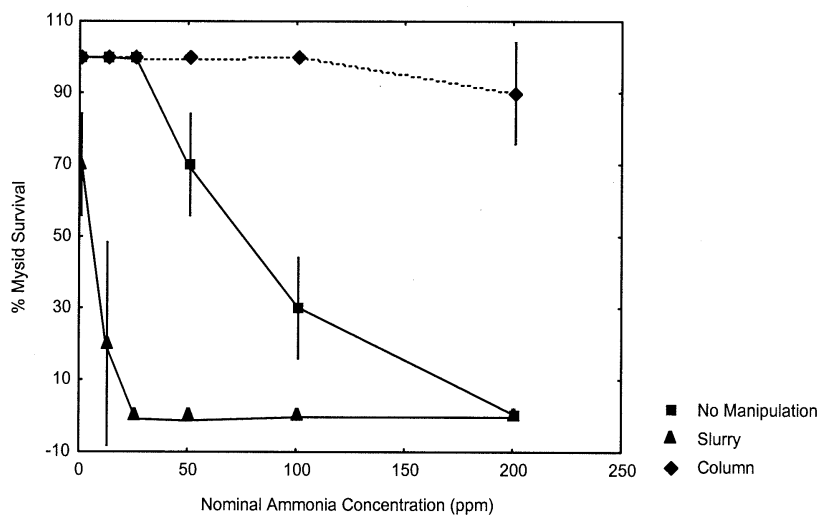

(b)

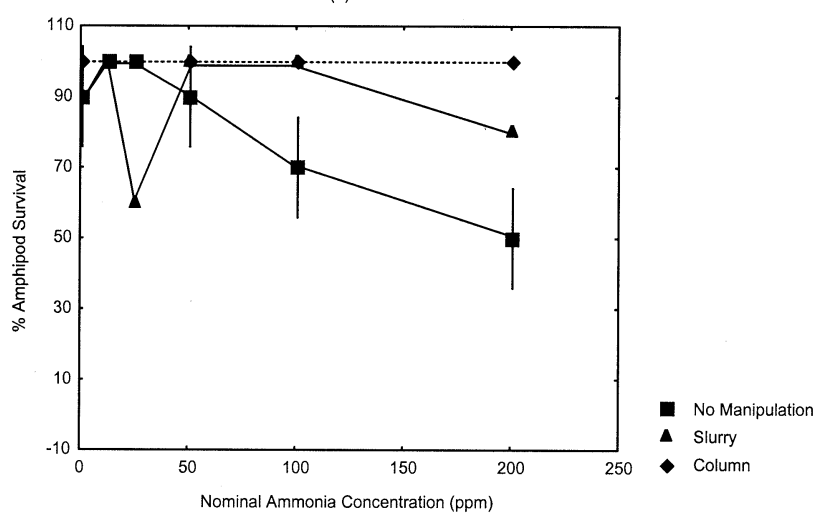

(c)

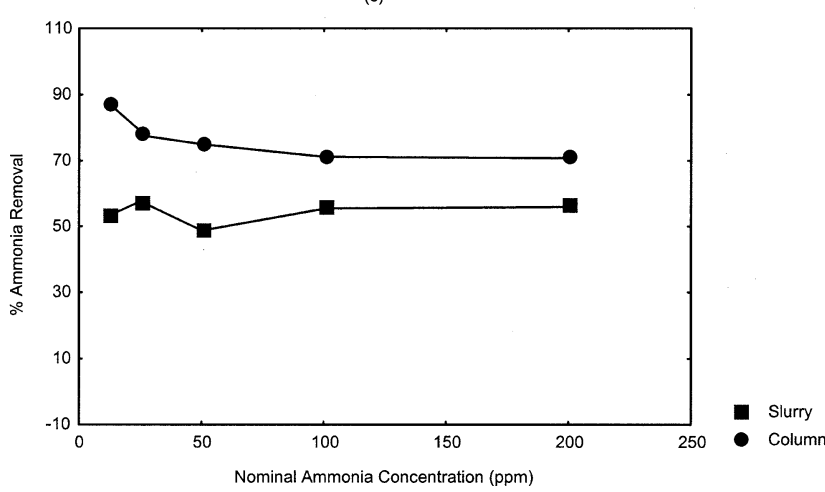

Fig. 7. Results of toxicity tests with ammonia in $30 \%$ RS solution. (A) Mysid survival. (B) Amphipod survival. (C) Ammonia removal

whereas the slurry resulted in greater toxicity than the unmanipulated treatment for the mysids and produced somewhat variable results for the amphipods. Causes of observed toxicity in the slurry treatment are not known, but the presence of very small zeolite particles or a toxic contaminant in the zeolite may be responsible. However, the slurry, like the column, was effective at decreasing ammonia concentrations (Fig. 7C). The column removed approximately $70-87 \%$ of the ammonia in the solutions, while the slurry removed approximately $53 \%$ to $56 \%$ (Fig. 7C). Toxicity to the amphipods did not exceed $50 \%$ even in the unmanipulated treatment, but both the slurry and the column treatments increased survival. For both species, column treatment increased survival to approximately $100 \%$ at all ammonia concentrations. The slurry, like the unmanipulated treatment, varied from $100 \%$ to approximately $0 \%$ survival for the mysids.

\section{Conclusions}

Based on the results of this study, we have concluded that use of zeolite in a column-chromatography design is an effective method for decreasing ammonia concentrations in seawater and decreasing ammonia toxicity to marine organisms. The column's performance decreased as a function of increasing salinity, but it always outperformed the slurry under similar conditions. The slurry design functions, but it has variable results compared with the column, and its efficacy was dependent on the salinity of the solutions. Also, as noted previously, the slurry method uses large amounts of zeolite compared with the column and consequently could be expensive to use routinely. Based on these results, the slurry design cannot be recommended; conversely, the column method is highly recommended despite being relatively time consuming and equipment intensive. When using the column method in the performance of a TIE with effluents and sediment interstitial waters, the other TIE manipulations, including the EDTA addition, should also be applied. Because zeolite will also remove metals from seawater, it is critical to include the EDTA manipulation to selectively assess the importance of metal caused toxicity in the samples being evaluated.

Acknowledgments. The authors thank Peter Meyers and the staff of ResinTech for providing helpful suggestions and plentiful zeolite to advance this research. The technical reviewers-Denise Champlin, James Heltshe (University of Rhode Island, Kingston, RI), Joseph LiVolsi, Wayne Munns, and Stephan Ryba-are also thanked for their insightful contributions. Mention of trade names or commercial products does not constitute endorsement or recommendation for use. This report was reviewed by the United States Environmental Protection Agency's National Health and Environmental Effects Research Laboratory, Atlantic Ecology Division, Narragansett, RI, and approved for publication. Approval does not signify that the contents necessarily reflect the views and policies of the agency. This is NHEERL-AED, Narragansett Contribution No. AED-03-111.

\section{References}

Ankley GT, Schubauer-Berigan MK (1995) Background and overview of current sediment toxicity identification evaluation procedures. Aquat Ecosystem Health 4:133-149

Besser JM, Ingersoll CG, Leonard EN, Mount DR (1998) Effect of zeolite on toxicity of ammonia in freshwater sediments: Implications for toxicity identification evaluation procedures. Environ Toxicol Chem 17:2310-2317

Burgess RM, Ho KT, Morrison GE, Chapman G, Denton DL (1996) Marine toxicity identification evaluation (TIE): Phase I guidance document (EPA 600/R-96/054) United States Environmental Protection Agency, Office of Research and Development, Washington, DC

Burgess RM (2000) Characterizing and identifying toxicants in marine 
waters: A review of marine toxicity identification evaluations (TIEs). Inter Environ Pollut 13:2-33

Burgess RM, Pelletier MC, Ho KT, Serbst JR, Ryba SA, Kuhn A, et al. (2003) Removal of ammonia toxicity in marine sediment TIEs: A comparison of Ulva lactuca, zeolite and aeration methods. Mar Pollut Bull 46:607-618

Durhan EJ, Norberg-King T, Burkhard LP (1993) Methods for aquatic toxicity identification evaluations: Phase II toxicity identification procedures for samples exhibiting acute and chronic toxicity (EPA/600/R-92/080). Environmental Research Laboratory, Duluth, MN

Hampson BL (1977) Relationship between total ammonia and free ammonia in terrestrial and ocean waters. Journal du Conseil International pour l'Exploration de la Mer 37:117-122

Ho KT, Kuhn A, Pelletier MC, Burgess RM, Helmstetter A (1999) Methods to distinguish $\mathrm{pH}$ dependent toxicants in marine waters using the macroalgae Ulva lactuca. Environ Toxicol Chem 18: 207-212

Ho KT, Burgess RM, Pelletier MC, Serbst JR, Ryba SA, Cantwell MG, et al. (2002) An overview of toxicant identification in sediments and dredged materials. Mar Pollut Bull 44:286-293

Kesraoui-Ouki S, Cheeseman CR, Perry R (1994) Natural zeolite utilisation in pollution control: A review of applications to metals' effluents. J Chem Technol Biotechnol 59:121-126

Mercer BW, Ames LL, Touhill CJ, Van Slyke WJ, Dean RB (1970) Ammonia removal from secondary effluents by selective ion exchange. J Water Pollut Control Fed 42:R95-R107

Millero FJ, Sohn ML (1992) Chemical oceanography. CRC, Boca Raton, FL

Norberg-King TJ, Mount D, Durhan E, Ankley G, Burkhard L, Amato J, et al. (1991) Methods for aquatic toxicity identification evaluations: Phase I toxicity characterization procedures, 2nd ed. (EPA/600/691/003). Environmental Research Laboratory, Duluth, MN

Pelletier MC, Ho KT, Cantwell M, Kuhn-Hines A, Jayaraman S, Burgess RM (2001) Use of Ulva lactuca to identify ammonia toxicity in marine and estuarine sediments. Environ Toxicol Chem 20:2852-2859

Rozic M, Cerjan-Stefanovic S, Kurajica S, Vancina V, Hodzic E (2000) Ammoniacal nitrogen removal from water by treatment with clays and zeolites. Water Res 34:3675-3681

United States Environmental Protection Agency (1989) Ambient aquatic life water quality criteria for ammonia (salt water) (EPA/ 440/5-88/004). Office of Research and Development, Atlantic Ecology Division, Narragansett, RI 